\title{
O que se ensina quando se ensina literatura? Considerações sobre a constituição de um objeto
}

\author{
What is taught when teaching literature? \\ Considerations about the constitution of an object \\ ¿Qué se enseña cuando se enseña literatura? \\ Consideraciones sobre la constitución de un objeto
}

Rita Jover-Faleiros ${ }^{*}$

\section{Resumo}

A partir da pergunta "o que se ensina quando se ensina literatura?", refletimos sobre a complexidade da relação entre os diferentes atores responsáveis pela constituição desse objeto de ensino e as forças em tensionamento entre os diferentes campos em comunicação para a constituição desse objeto, notadamente os estudos literários e a didática, que acabam por produzir clivagens nos modelos de ensino de literatura em vigor hoje no Brasil. A partir de uma síntese de diagnósticos sobre a temática, identificamos nas propostas de círculos de leitura entre pares (Hébert, 2010) uma abordagem do literário em contexto escolar que nos parece articular os saberes dos diferentes campos constitutivos de uma didática do texto literário.

Palavras-chave: ensino da literatura, didática, círculos de leitura.

\begin{abstract}
Reflecting on the question "what is taught when teaching literature?" this article elaborates on the complex relationship between the different actors responsible for the constitution of this object of teaching as well as the conflicting forces between the different fields in communication that make up this object, especially literary and didactic studies that end up producing cleavages in the models of literature teaching in force in Brazil today. From a synthesis of diagnostics on the subject, we identify in the proposals of reading circles among peers (Hébert, 2010) an approach to the literary in an educational context that seems to us to articulate the knowledge of the different constituent fields of a literary didactics.
\end{abstract}

Keywords: teaching literature, didactics, literature circles.

\section{Resumen}

A partir de la pregunta "¿qué se enseña cuando se enseña literatura?" reflexionamos sobre la complejidad de la relación entre los diferentes actores responsables para la constitución de ese objeto de enseñanza y las fuerzas en tensión entre los diferentes campos en comunicación para la constitución de ese objeto, notoriamente los estudios literarios y la didáctica, que acaban por producir brechas en los modelos de la enseñanza de la literatura en vigor hoy en Brasil. A partir de una síntesis de diagnósticos sobre la temática, identificamos en las propuestas de círculos de lectura entre pares (Hébert, 2010) un abordaje delo literario en contexto escolar que nos parece articular los saberes de los diferentes campos constitutivos de una didáctica del texto literario.

Palabras clave: enseñanza de la literatura, didáctica, círculos de lectura.

Instigada pelas questões relacionadas à constituição desse objeto de ensino tão singular que é a literatura e pelo modo como a conversa sobre o assunto costuma enveredar para temas relativos à sala de aula, costumo fazer a pergunta enunciada no título a colegas-amigos professores do ensino básico e superior. Em comum, um primeiro silêncio hesitante diante da pergunta à queima roupa, em seguida, respostas distintas em função das diferentes inscrições institucionais, dos diferentes públicos e das diferentes visadas teóricas.

\footnotetext{
* Doutora em letras e professora da Universidade Federal de São Paulo (Unifesp), Guarulhos, SP, Brasil. (Dorcid.org/0000-00028859-5808. E-mail: rita.jover@unifesp.br.
} 
Esses diálogos, em geral, oferecem respostas espontâneas e heterogêneas que levam a refletir sobre a natureza da pergunta e do primeiro silêncio hesitante que costuma gerar. Se as respostas podem ser circunstanciais e transitórias, segue viva a necessidade da pergunta, por ela permitir que se discutam a complexidade da constituição do objeto de ensino e os diferentes atores em cena nesse processo. ${ }^{1}$ Dessa forma, a formulação da pergunta implica assumir que o ensino da literatura está constituído por essa transitividade de ordem social e histórica e que, por isso, as respostas a ela não poderiam deixar de ser transitórias e circunstanciais. Nesse sentido, uma relativa reticência em relação à constituição desse objeto, ou até mesmo uma desconfiança em considerá-lo como um objeto de ensino construído e informado por saberes de referência e práticas sociais de diferentes ordens e origens, tem uma inscrição histórica que relaciona literatura à crise no contexto educacional, como atestam obras publicadas ao longo dos últimos quarenta anos no Brasil e fora dele (Mortatti, 2018; Gabathuler, 2016; Jover-Faleiros 2013).

Com efeito, o binômio ensino e literatura no Brasil é tema cuja produção é profícua, mas, não raro, uma revisão da produção acadêmica sobre a temática registra palavras como "impasse", "aporia", "desafio", "dificuldade" associadas a ele. Não são poucos os diagnósticos e as propostas metodológicas para a mudança do quadro atual. ${ }^{2}$ Parece-me que um dos fulcros da origem desse impasse reside em um tensionamento entre literatura e educação. Como analisado por Nakagome (2015, p. 90), essas noções se operariam até em alternância e o binômio literatura e educação poderia traduzir uma oposição entre literatura ou educação:

A relação de adição entre literatura e educação se faz mais frágil quando a Literatura, aquela intencionalmente grafada com letras maiúsculas, é o ponto de partida para a reflexão. Se por um lado há um número crescente de relevantes pesquisas sobre possibilidades de trabalhar a literatura na sala de aula, por outro, não parece haver a proporcional atenção da crítica literária em relação à circulação mais ampla das obras, o que inclui, evidentemente, o espaço escolar.

A partir da análise de um texto crítico publicado por Milton Hatoum no jornal O Estado de $S$. Paulo, a pesquisadora identifica, no discurso do autor, que opõe a literatura canônica da Europa ocidental à literatura de massa, a impossibilidade de a escola no Brasil formar novos leitores de Flaubert, Stendhal e Conrad. O texto de Nakagome parece identificar o modo como Hatoum se exime da responsabilidade diante do problema que ele próprio diagnostica:

Sem o olhar aberto aos leitores de diferentes obras, alguns leitores se sentem solitários, culpando o Estado (materializado na instituição da escola) como grande responsável por sua solidão. Diante disso, a atitude de um autor como Hatoum restringe-se a um julgamento que faz eco aos tantos "diagnósticos" da precariedade da educação, sem jamais cogitar a possibilidade de se atuar sobre esse espaço (Nakagome, 2015, p. 99).

Dessa forma, o tensionamento entre as diferentes manifestações literárias, seus suportes e sua relação com o "leitor comum" é uma das discussões que atravessam o debate sobre a crise do ensino da literatura. Uma espécie de fatalismo e nostalgia diante das transformações sociais que se manifestam no sistema literário, transformações essas que deveriam também se traduzir na forma e nos objetivos de seu ensino. Como assinala Nakagome em seu texto, uma das tarefas do crítico literário é conhecer o leitor que se interessa por obras que não fazem parte da tradição literária e, ao conhecê-lo, promover uma mediação com vistas ao acesso desse leitor a essa tradição. Se esse tensionamento é constitutivo da discussão sobre a formação de leitores na e pela escola, como também discute Abreu em seu Cultura letrada, literatura e leitura (2004), a oposição entre alta

\footnotetext{
${ }^{1}$ Toda situação de aprendizagem é definida, a partir dos trabalhos na área da didática, como compostos por uma tríade: saber a ser ensinado, professor e aluno (Halté, 1992).

${ }^{2}$ A título de ilustração, no dossiê "Leitura e escrita literária na Educação Básica. O que tem a dizer a pesquisa contemporânea", organizado por Maria Amélia Dalvi e Elisa Maria Dalla-Bonna (2014), identificamos "problemas" (Mortatti, 2014), "obstáculos" (Tauveron, 2014), "problemática brasileira do ensino da literatura no nível médio [...] o grave problema da formação precária de leitores na escola" (Alves, 2014), "A intricada leitura de literatura" (Tinoco, 2014). Para o desenvolvimento da discussão, ver Rezende e Dalvi (2011), Jover-Faleiros (2013), Rezende e Oliveira (2015).
} 
literatura e literatura de massa parece ser sintomática de algo mais dificilmente discernível no debate, ou seja, a própria constituição dos saberes de referência no campo.

É para essa questão que Diniz (2016) volta o olhar ao discutir deslocamentos dentro do campo teórico dos estudos literários e suas implicações. A pesquisadora aponta as possíveis contribuições de uma abordagem do literário em contexto escolar a partir de uma reorientação dos pressupostos teóricos da representação e da busca pela construção de sentido como finalidade para a formação do leitor literário. Para Diniz (2016, p. 148), é necessário que "teóricos e estudiosos da literatura" possam contemplar uma abordagem do literário menos "avessa à participação da subjetividade, menos circunscrita e limitada". Sem me deter no interessante itinerário teórico por ela desenhado, chamo aqui a atenção para o fato de a autora recuperar um conceito tradicional para repensá-lo de modo produtivo visando ao desenvolvimento de uma reflexão sobre a própria relação que estabelecemos, nós, os professores, com a literatura.

Essa convergência identificada entre as proposições desenvolvidas por Nakagome (2015) e Diniz (2016) aponta para uma problemática interna aos estudos literários e seu ensino, a saber, uma certa sacralização da cultura letrada, que recorta uma seleção do que deve ser e como deve ser lido o texto literário em contexto escolar, talvez até em detrimento dos interesses e gostos dos leitores em formação. Além disso, indica uma clivagem externa na constituição do objeto de ensino e sua articulação entre os saberes de referência dos estudos literários e os saberes de outros campos, como a didática. Isso significa que, para a constituição desse objeto de ensino, é também necessário conhecer e considerar o alunoleitor como sujeito na relação com o que lê e aprende nas aulas de literatura.

Nesse sentido, Alves (2014, p. 13) observa uma clivagem entre esses campos na apresentação da obra Memórias da Borborema 4: discutindo a leitura e seu ensino: "A palavra didática entre críticos literários e muitos professores de literatura assumiu um sentido negativo, de facilitação, de superficialidade. Resgatar o sentido positivo desta área do saber constitui-se quase um imperativo, sobretudo quando se pensa em formar leitores".

Assim, uma das questões que alimenta esse impasse está diretamente relacionada à constituição desse objeto de ensino, que deveria articular três campos distintos de conhecimento: os estudos literários e seus saberes de referência (Chevallard, 1991) legitimados pela comunidade científica como aquilo que se deseja transmitir às novas gerações nas diferentes etapas do processo de escolarização; os estudos na área da educação e mais especificamente na didática da disciplina de língua portuguesa, na qual está inscrita a didática da literatura; e, por fim, os estudos na área da psicolinguística cognitiva que descrevem os processos de construção de sentido no ato da leitura e que podem subsidiar as abordagens - do ponto de vista metodológico - do texto literário em contexto de ensino e de aprendizagem.

Outro aspecto para o qual apontam os diagnósticos sobre a formação de leitores literários na escola é o aparente descompasso entre a representação da leitura como uma atividade de fruição, uma relação singular, solitária e silenciosa entre texto e leitor (um hábito que deseja transmitir aos jovens na escola, pois socialmente legitimado) e a leitura de textos literários empreendidas no ensino básico, sobretudo no ensino médio, que, em certa medida, reproduzem um modo de se ler o literário calcado nas práticas desenvolvidas no âmbito da pesquisa em nível superior na área das Letras.

Os números apurados pelas sucessivas edições da pesquisa Retratos da leitura no Brasil (Failla, 2016) mostram um decréscimo contínuo do número de jovens que afirmam gostar de ler à medida que avançam para os anos finais do ensino básico. Ao se considerar, também, de acordo com o que registra a referida pesquisa, o quase inexpressivo papel desempenhado pelos professores na origem do interesse pela leitura dos jovens, parece claro que a clivagem entre o prazer de ler e o dever de ler na escola é um sintoma da forma como a constituição do objeto - o que se ensina quando se ensina literatura - parece não contemplar uma relação singular, individual e, de certo modo, voluntária como uma prática a ser estimulada. Paradoxalmente, apesar de haver consenso sobre o interesse em se promover o gosto pela leitura na escola, o modo como ela se torna um objeto de ensino geraria um efeito contrário, afastando o gesto voluntário e de fruição em nome 
das necessidades e restrições institucionais de diversas ordens (livros didáticos e sistemas apostilados de ensino; instruções governamentais, formação e atualização do corpo docente; condições de infraestrutura do ponto de vista das bibliotecas, do números de alunos por sala, o imperativo da avaliação, a preparação para os exames vestibulares). Em outras palavras, é como se o gosto pela leitura se desenvolvesse apesar da escola.

Em síntese, operamos em duas ordens de clivagem que se sobrepõem. De um lado, a falta de comunicação entre os diferentes campos de conhecimento que deveriam informar a constituição das práticas de ensino da literatura e de formação de leitores literários; de outro, uma clivagem interna entre representações de leitura distintas em que a apropriação de instrumentos teóricos e estratégias específicas oriundas dos estudos literários prepararia a leitura solitária (e de fruição). Essa é, aliás, a hipótese defendida por grupos de pesquisadores da comunidade internacional da área da didática do literário, ${ }^{3}$ como pode ser observado em dossiê sobre as interações e mediações em aula de literatura organizado pela revista Enjeux de didática do francês (2003); posição reafirmada no capítulo dedicado ao ensino de literatura na obra de referência da área de didática da língua francesa Didactique du Français langue première (Simard et al., 2016).

Além das considerações apresentadas até aqui, do ponto de vista do que efetivamente é realizado em sala de aula, é pertinente atribuir parte dos insucessos relativos à formação dos leitores em razão das condições de infraestrutura do ensino público no Brasil. Dentre as muitas razões que concorrem para a configuração desse quadro, destaca-se o fato de que os contextos de ensino no país são heterogêneos no que concerne às regiões, às realidades socioeconômicas do território nacional, às diferenças de infraestrutura entre o ensino privado e o público. Evidencia-se, pois, um descompasso entre o desenvolvimento da pesquisa na área e a realidade verificada, referente a indicadores de avaliação de leitura.

Nesse sentido, Rezende (2013) identifica expressivo desarranjo entre as instruções oficiais para o ensino da leitura e da leitura literária e o que se observa na realidade dos contextos escolares, e isso de duas formas: em relação às condições materiais oferecidas, sobretudo no contexto do ensino público, e em relação às práticas efetivas em sala de aula. Dentre os fatores de ordem material, encontram-se a precariedade das instalações, a falta de acervo ou de pessoal especializado para manuseio do acervo, entre outros.

Quanto às práticas efetivas, observa-se que ainda somos demasiadamente tributários de um modelo de ensino da literatura "monumentalista" (Hébert, 2010), em que o que está em jogo é ilustrar a história das escolas literárias por meio de trechos de autores célebres para a formação do cânone. Modelo esse ainda predominante em cursos de Letras e de Licenciatura em Letras, sobretudo nas instituições de ensino privado - responsáveis pela formação do maior contingente de professores da rede pública do ensino básico. Outra dimensão dessa visada se traduz, para Rezende, em um conservadorismo da escola brasileira, resistente a integrar novas tecnologias da informação às práticas de leitura e que, ao mesmo tempo, negligenciaria novas modalidades de aquisição de conhecimentos desenvolvidas pelos jovens alunos na interação com essas novas tecnologias.

Dessa forma, a escola brasileira, de um modo geral, tenderia a manter essa abordagem em detrimento das orientações curriculares e da produção editorial com finalidade didática da última década, em que preponderam abordagens inspiradas pelas teorias cognitivistas e sócioconstrutivistas e pelos trabalhos dos estudos da recepção, abordagens que privilegiaram a relação de interação texto-leitor, e não uma ênfase orientada para a transmissão de conteúdos. Entendo que esse descompasso verifica-se na (ainda) atual impossibilidade, apesar dos esforços empenhados por diversos agentes, de fomentar práticas de ensino que efetivamente se desloquem de um ensino da literatura para um ensino da leitura literária.

Diante da complexidade do quadro, há relativo consenso quanto ao desafio atual, isto é, o papel e o lugar acordados à leitura literária nessa formação. Ainda que esse consenso se decline

\footnotetext{
${ }^{3}$ É possível identificar nesse sentido uma hipótese teleológica em que a preparação por meio de acesso ao instrumental teórico sobre a literatura conduziria ao desenvolvimento do gosto pela leitura literária pelas razões adequadas?
} 
em respostas distintas em função das diferentes abordagens, filiações teóricas e propostas de intervenção didática, uma renovação teórico-metodológica parece se impor.

\section{Círculos de leitura: das clivagens às perspectivas de articulação}

No Brasil, uma das propostas que buscam responder aos indicadores acima referidos quanto à formação dos leitores é a da formação de círculos de leitura em contexto escolar e não escolar (Yunes, 1999; Cosson, 2014). Assim, no que concerne especificamente ao campo de estudos deste trabalho, em seu texto intitulado "Círculos de leitura: teoria e prática", Yunes (1999) oferece como caminho uma "estratégia de sedução" para atrair os jovens para a leitura literária. Seu dispositivo é bastante aberto e as orientações para a formação dos círculos não são estruturadas para operar especificamente em contexto didático. A autora ampara sua proposta na tradição de leitura literária contada oralmente em comunidades onde o livro ainda era um objeto raro e os leitores, pouco numerosos. Para Yunes, os círculos de leitura promoveriam uma experiência positiva de convivialidade na formação para a leitura, o que poderia se desdobrar no desenvolvimento, entre os jovens, do prazer de ler.

Diante do mesmo quadro, Cosson (2014) propõe, na obra Círculos de leitura e letramento literário, a constituição de círculos de leitura na senda dos trabalhos de Elizabeth Long (1993) e Harvey Daniels (2002). O autor relata o sucesso das experiências com a prática dos círculos nos Estados Unidos em contextos escolares e não escolares. As possíveis aplicações do modelo no Brasil, bem como as adequações necessárias inerentes às singularidades locais, ainda permanecem, contudo, como algo a ser desenvolvido.

Com efeito, Yunes e Cosson contribuíram para a difusão dos círculos de leitura no país prática essa já bastante difundida em países anglófonos como os Estados Unidos, Canadá e Inglaterra - bem como com o recenseamento dessa atividade no Brasil na atualidade (notadamente Cosson, 2014), mostrando como se trata de atividade que vem ganhando espaço em contextos não didáticos entre leitores adultos. Não se identifica, contudo, nem uma descrição pormenorizada de suas etapas nem um acompanhamento que permita a análise de seus resultados, o que pode levar a crer que o dispositivo dos círculos de leitura é pensado, por Yunes e Cosson, como uma abordagem da leitura literária a ser realizada fora da sala de aula, seja em sua dimensão física material, seja em sua dimensão simbólica como atividade didática. ${ }^{4}$

Assim, os trabalhos que se propõem a desenvolver círculos de leitura no Brasil (ao menos aqueles a que tivemos acesso) não chegam a propor uma organização metodológica estruturada na forma de atividades. Entendo que o conjunto dessas propostas traduz uma percepção que inscreve a leitura literária não como um objeto de ensino e de aprendizagem, mas, sim, como algo a ser realizado no exterior da sala de aula, afastando-se assim dos recursos de ordem didático-metodológicos que possam vir a contribuir para a formação de leitores literários. Nesse sentido, as propostas parecem buscar responder uma das ordens de clivagem que destaco: a busca pela criação de ambientes propícios para o desenvolvimento de um gosto pela leitura talvez pela própria recusa de inscrever as atividades didáticas em sala de aula, reconfigurando-as não como objetos de ensino informados por saberes de referência, mas recuperando sua dimensão de sociabilidade (o compartilhamento de leituras) não mediados pelos aparatos teóricos oriundos dos estudos literários.

O conjunto dessas propostas aponta para um dos impasses relativos ao papel desempenhado pela literatura na escola, que é o de desconfigurar a relação do leitor com o texto literário. Assim, ao transformar o texto literário em um objeto de ensino, a escola não o contemplaria como um espaço de prazer e de evasão, tampouco como um espaço de experiência de subjetividade e também de alteridade. Relação essa fartamente registrada por relatos de

\footnotetext{
${ }^{4}$ Nos artigos de Souza (2012) e Pereira (2015) bem como na tese de doutorado de Gonçalves (2015), desenvolvida a partir dos trabalhos de Yunes (1999), parece-nos difícil identificar os objetivos tanto de ordem teórica quanto metodológica que justificariam as razões por que os círculos de leitura poderiam vir a contribuir para o desenvolvimento da leitura literária e do prazer de ler entre os jovens leitores.
} 
leitores de toda ordem como, por exemplo, por Clarice Lispector, no conto "Felicidade clandestina". Nele, a narradora descreve as agruras experienciadas para ter acesso a um livro e, uma vez em posse dele, a relação que estabelece com sua leitura:

Chegando em casa, não comecei a ler. Fingia que não o tinha, só para depois ter o susto de o ter. Horas depois, abri-o, li algumas linhas maravilhosas, fechei-o de novo, fui passear pela casa, adiei ainda mais indo comer pão com manteiga, fingi que não sabia onde guardara o livro, achava-o, abria-o por alguns instantes. Criava as mais falsas dificuldades para aquela coisa clandestina que era a felicidade (Lispector, 1971, p. 10).

Assim como o relato da narradora do conto de Lispector sobre a menina leitora que foi, tantos outros são os relatos ficcionais e históricos que descrevem os modos de ser leitor e os diferentes gestos de leitura implicados no processo (Bayard, 2008; Manguel, 2001; Jover-Faleiros, 2013). Destaca-se, entretanto, que um número expressivo desses relatos parecem apontar para uma clivagem entre a leitura literária dentro e fora da escola:

São, pois, bastante diversas as experiências e figurações de leitura, mas parece haver relativo consenso nos diferentes registros a propósito do ensino da literatura. Diante dessa aparente crise de objeto, há como uma de suas consequências, a manifestação dessas figurações dos leitores clivados - a se considerar as colocações de Perrone-Moisés, Rouxel e Todorov -, alunos que experienciam vivências pulsantes como leitores literários fora de contexto escolar, mas que leriam textos literários na escolar sem grande interesse. [...] falta trazer o mundo em escala reduzida para experiência da leitura literária em sua dimensão individual e coletiva em contexto didático (Jover-Faleiros, 2013, p. 120).

Um exemplo importante são os dados oferecidos pela já citada série histórica da pesquisa Retratos da Leitura no Brasil (Galeno, 2008; Failla, 2012; Failla, 2016), numericamente expressivos e de âmbito nacional. Eles corroboram essa percepção que desarticula a leitura funcional, realizada na escola, da leitura prazerosa, realizada fora do contexto escolar. Ainda que não seja o objetivo principal desta pesquisa, vale salientar que, no estudo intitulado "Retratos da leitura, retratos do leitor: gestos, espaços, hábitos" (Jover-Faleiros, 2018), aponto para o fato de que, no conjunto das sucessivas edições da pesquisa, a representação da leitura predominante é de uma atividade instrumental, associada à escola. Talvez a pesquisa Retratos mostre, pois, como efetivamente a leitura está presente em nossas vidas: na maior parte do tempo ela seria um meio para outro fim e se realizaria de forma predominante na escola.

São, pois, bastante diversas as experiências e figurações de leitura, mas parece haver relativo consenso nos diferentes registros a propósito do ensino da literatura. Diante dessa aparente crise de objeto, há, como uma de suas consequências, a manifestação dessas figurações dos leitores clivados, alunos que experienciam vivências pulsantes como leitores literários fora de contexto escolar, mas que leriam textos literários na escola sem grande interesse.

Diante dessa clivagem que parece existir entre o dever ler e o prazer de ler, que parece informar os trabalhos de Yunes e Cosson e que os exemplos aqui oferecidos ilustram, podemos levantar algumas questões. Será que, como apontam alguns pesquisadores da área de ensino da leitura literária, como Rouxel (2012), Langlade (2004) e Jouve (2012), existe uma articulação possível entre esse dever e esse prazer de ler a ser desenvolvida? Essa articulação se daria pela via da experiência do sujeito leitor que se apropria e atribui sentido a essa atividade? Isso implicaria o desenvolvimento de uma autonomia do leitor em relação à instituição escolar, tensionando as expectativas individuais do leitor quanto às expectativas institucionais da escola? Esse tensionamento poderia vir a ser um espaço de mediação a ser exercido pelo professor?

Face ao que se discutiu, é preciso refletir quais são contribuições possíveis dos saberes de referência oferecidos pelos estudos literários na busca por uma reorientação dos saberes a serem ensinados com vistas à constituição do objeto de ensino, por um lado e, por outro, como articular esses saberes de referência às contribuições da didática e da psicologia cognitiva como forma de subsidiar a ação do professor do ponto de vista metodológico. 
Se as propostas de círculo de leitura divulgadas atualmente inscrevem a leitura literária num lugar extradidático, que me parecem contemplar um modo de leitura não prescritivo e, nesse sentido, talvez mais próximo de oferecer uma experiência mediada de leitura pautada pela expressão de uma subjetividade em relação ao lido, elas, de certa forma, ratificam a hipótese de que é difícil conciliar a experiência de leitura literária (em sua dimensão subjetiva e, pois, individual) e o ensino da literatura. Essas propostas se constituiriam em uma terceira via: nem literatura (com o instrumental teórico para apreciação da literatura canônica), nem ensino (pois recusando as sistematizações metodológicas oferecidas pela didática). O objetivo último dessa terceira via seria a emulação do gesto de leitura de fruição e da sociabilização do que é lido. Ainda que se trate de lugar pertinente e necessário, parece-me que tanto no âmbito da docência quanto no da pesquisa é importante que se desenvolvam abordagens que inscrevam os círculos de leitura dentro da sala de aula, fazendo da leitura literária um objeto de ensino e de aprendizagem que mobilize saberes relativos aos modos de aquisição e de aprendizagem da atividade da leitura, bem como a reflexão teórica concernindo a literatura como objeto estético.

Nesse sentido, uma proposta que me parece contemplar essas três dimensões para a constituição de um objeto de ensino consiste no dispositivo de círculos de leitura entre pares (CLP), desenvolvido pela pesquisadora Manon Hébert (2006), da Universidade de Montréal. A pesquisadora inicia sua trajetória no desenvolvimento desse dispositivo nos anos 1990, quando se torna professora de língua francesa na província de Québec, Canadá, nos anos iniciais do ensino secundário quebequense (o que no Brasil equivaleria ao ensino fundamental II) e depara com três dificuldades: transpor para a sala de aula aquilo que aprendeu em sua formação literária, transmitir seu gosto pela leitura e, por último, mas não menos importante, atender a uma diretiva governamental que previa a leitura de no mínimo três obras integrais ao longo de um ano letivo.

O primeiro resultado dessa busca se transforma em uma tese de doutorado, defendida em 2002, na qual a pesquisadora articula o ensino explícito de estratégias de leitura ao ensino de noções literárias nas diferentes etapas da leitura de uma obra literária em um CLP. Naquilo que nomeia um "ensino transacional da literatura", a autora reúne as teorias sócioconstrutivistas (Vygostki, 1997), cognitivas (Giasson, 2003; Tardif, 1992) e estéticas (Rosenblatt, 1994) da leitura para responder, sob a forma de uma pesquisa-ação, a impasses que viveu como professora no ensino básico, impasses que se assemelham significativamente àqueles discutidos neste artigo.

Trata-se de uma proposta que desenvolve um dispositivo de ação em sala de aula por meio da construção de grupos de leitura formado por alunos. Nesses grupos, a construção de sentido tem uma dimensão de ordem individual (pressupõe uma leitura prévia registrada em diário de leitura que tem como um dos objetivos o de registrar as estratégias para leitura e construção de sentido) e uma de ordem coletiva, que consiste na realização dos círculos, nas trocas a propósito desse processo de leitura do ponto de vista das estratégias bem como ao resultado desse processo de construção de sentido. O dispositivo do CLP prevê o acompanhamento e a análise de cada uma das diferentes etapas, registrando os encontros dos CLP. Trata-se de um trabalho de pesquisa cuja repercussão se desdobra no próprio modo de trabalhar os CLP, bem como, potencialmente, no desenvolvimento das teorias da leitura em suas diferentes visadas.

Destaco, em síntese, ${ }^{5}$ três linhas de força da pesquisa que vem sendo desenvolvida pela pesquisadora na rede pública do ensino secundário da região de Montréal. Em primeiro lugar, um dos destaques da pesquisa por meio dos CLP reside na articulação concomitante da preparação e da formação dos professores dispostos a integrar os CLP às suas práticas (o que implica questionamentos e ressignificações por parte desses professores quanto à formação de seus alunos-leitores). Em segundo lugar, a organização dos círculos e seu registro por meio dos diários de leitura e das gravações em vídeo dos encontros de leitores em sala de aula propicia farta documentação para análise, capaz de oferecer subsídios - com base na observação da construção de sentido de alunos-leitores empíricos no ato da leitura - seja para o desenvolvimento da pesquisa no campo, seja para que o professor tenha acesso ao processo de

\footnotetext{
${ }^{5}$ A análise integral e detalhada do dispositivo é objeto de pesquisa em curso, cujos resultados serão divulgados a posteriori em publicação com este fim.
} 
aprendizagem de seus alunos-leitores. Por fim, o acompanhamento do desenvolvimento desses alunos ao longo de um ano letivo por meio dos registros dos professores envolvidos oferece uma visada do conjunto dos atores em contexto envolvidos no processo. Identifica-se, pois, no dispositivo, a articulação das diferentes frentes a serem desenvolvidas no que concerne ao ensino da leitura e da leitura literária (as dimensões do texto, contexto e leitor, mas também a constituição de um objeto de ensino e uma metodologia clara que trata das diferentes etapas do dispositivo em seu plano micro e macro). Em segundo lugar, trata-se de uma pesquisa que emerge de um problema concreto experienciado em sala de aula: como realizar leituras de obras literárias integrais em sala de aula e como traduzir em propostas concretas as respostas a esse problema? Em terceiro lugar, a pesquisa trabalha o ensino e a aprendizagem de três competências de maneira articulada: a compreensão/interpretação, o desenvolvimento da expressão oral (justificar, parafrasear sobretudo) e o contato com saberes do campo dos estudos literários (com vistas ao desenvolvimento das duas outras competências/habilidades). Finalmente, a pesquisa foi desenvolvida com um amplo espectro de estudantes do ensino básico em contextos distintos, como podemos observar por meio dos resultados (Lafontaine e Hébert, 2015).

\section{Considerações finais}

A constituição de um objeto de ensino é o resultado, como vimos, da relação entre diversos atores em um contexto que é, simultaneamente, institucional, científico e social. Perguntar-se sobre o que se ensina quando se ensina literatura faz com que possamos refletir sobre os tensionamentos, predominâncias, hierarquias e narrativas sobre como se dão, ao fio do tempo, as intrincadas relações entre esses atores que intervêm na intersecção do sistema de ensino e da sociedade, o que Chevallard (1991) denomina noosfera. Refletir sobre a pergunta também implica aceitar que as respostas são plurais tanto do ponto de vista diacrônico quanto sincrônico. Da constituição de um campo, da composição de disciplinas informadas por esse campo, dos sucessivos recortes operados para a formação de seus objetos de ensino, das disputas no interior dos diferentes campos ou entre eles, aqui foram discutidos o campo dos estudos literários e a relação entre os estudos literários e a educação.

Apontadas algumas das clivagens que parecem ser, em parte, responsáveis pelo pouco sucesso dos modelos de ensino de literatura em vigor, foram identificadas as propostas de círculos de leitura que buscam responder às limitações analisadas pelos numerosos diagnósticos sobre essa temática. Dentre essas propostas, é possível identificar uma primeira - os círculos de leitura propostos sobretudo por Yunes $(1999,2002)$ e Cosson $(2014)$ - que inscreve essa prática como uma iniciativa de promoção da leitura fora de um enquadramento formal do espaço da sala de aula, recuperando uma inspiração, entendo, orientada por uma emulação de um gesto de leitura como experiência de compartilhamento. Uma segunda proposta, a dos círculos de leitura entre pares, dispositivo desenhado por Hébert (2008), promove a leitura literária circunscrita ao espaço didático, mobilizando saberes de referência dos estudos literários, da educação e da psicologia cognitiva em busca de abarcar, por meio da amplitude da proposta, um conjunto de atividades que possa considerar o sujeito leitor como centro de um dispositivo de ensino, e sua experiência de leitura - subjetiva - como algo a ser compartilhado e sobre o qual um discurso sobre a aprendizagem se constrói.

Por fim, cabe sinalizar que defendi ao longo deste texto a importância de entendermos que as respostas possíveis ao impasse da formação de leitores literários na e pela escola não passam apenas por uma renovação metodológica. É preciso considerar, ainda, a necessária articulação entre os diferentes campos de conhecimento e manter em mente que esses impasses não são oriundos apenas das vicissitudes do sistema escolar brasileiro e sua - permanente? - crise de financiamento, visto que sistemas escolares mais bem financiados na Europa e América do Norte sofrem de diagnósticos que podem se aproximar dos nossos quando o tema é o ensino da literatura. 


\section{Referências}

ABREU, Márcia (2004). Cultura letrada, literatura e leitura. São Paulo: Unesp.

ALVES, José Helder Pinheiro (Org.) (2014). Memórias da Borborema 4: discutindo a literatura e seu ensino. Campina Grande: Abralic.

BAYARD, Pierre (2008). Comment parler des livres qu'on pas lus? Paris: Les Éditions de Minuit.

CHEVALLARD, Yves (1991). La transposition didactique: du savoir savant au savoir enseigné. Paris: La Pensee Sauvage.

COSSON, Rildo (2014). Círculos de leitura e letramento literário. São Paulo: Contexto.

DALVI, Maria Amélia; DALLA-BONA, Maria Elisa (Orgs.) (2014). Apresentação. Dossiê Leitura e escrita literária na educação básica. O que tem a dizer a pesquisa contemporânea? Educar em Revista, Curitiba, v. 30, n. 52, p. 17-21, abr./jun.

DANIELS, Harvey (2002). Literature circles: voice and choices in Book Clubs and Reading Groups. Portland, Maine: Stenhouse Publishers.

DINIZ, Lígia Gonçalves (2016). O mundo nos textos literários: releituras da interpretação e possibilidades em sala de aula. Literatura e sociedade, São Paulo, v. 21, n. 23, p. 139-162.

FAILLA, Zoara (Org.) (2016). Retratos da leitura no Brasil. Rio de Janeiro: Sextante.

GIASSON, Jocelyne (2003). La lecture: théorie et pratique. Québec: Gaetan Morin.

GABATHULER, Chloé (2016). Apprécier la littérature. Rennes: Presses Universitaires de Rennes.

GONÇALVES, Luciana Sacramento Moreno (2014). Os jovens em círculos de leitura literária: uma proposta para espaços alternativos. Tese (Doutorado em Letras) - Pontíficia Universidade Católica do Rio Grande do Sul, Porto Alegre.

HALTÉ, Jean François (1992). La didactique du français. Paris: Presses Universitaires de France.

HÉBERT, Manon (2006). Une démarche intégrée et explicite pour enseigner à "apprécier" les oeuvres littéraires. Québec Français, Montréal, n. 143, p. 74-76.

HÉBERT, Manon (2008). Le journal de lecture comme genre d'écrit réflexif. Québec Français, Montréal, n. 149 , p. 65-66.

HÉBERT, Manon (2010). Co-élaboration du sens dans les cercles littéraires entre pairs. Paris: Editions Européennes.

JOVER-FALEIROS, Rita (2013). Sobre o prazer e o dever ler: figurações de leitores e modelos de ensino da literatura. In: DALVI, Maria Amélia; REZENDE, Neide; JOVER-FALEIROS, Rita (Orgs.). Leitura de literatura na escola. São Paulo: Parábola. p. 113-133.

JOVER-FALEIROS, Rita (2018). Retratos da leitura, retratos do leitor: gestos, espaços e hábitos. Água viva, Brasília, v. 3, p. 10-27.

JOUVE, Vincent (2012). A leitura como retorno a si: sobre o interesse pedagógico das leituras subjetivas. In: ROUXEL, Annie; LANGLADE, Gérard; REZENDE, Neide (Orgs.). Leitura subjetiva e ensino de literatura. São Paulo: Alameda. p. 55-67.

LAFONTAINE, Lizaine; HÉBERT, Manon (2015). Quelques effets de l'enseignement de l'oral en situation de cercles de lecture. Québec Français, Montréal, n. 174, p. 19-20.

LISPECTOR, Clarice (1981). Felicidade clandestina. Rio de Janeiro: Nova Fronteira.

LONG, Elizabeth (1993). Textual interpretation as collective action. In: BOYARIN, Jonathan (Ed.). The ethnography of reading. Berkeley: University of California Press.

PEREIRA, Valéria Cristina Ribeiro (2015). Dados para o subsídio a práticas da leitura de literatura na escola: um círculo de leitura. Contexto, Vitória, v. 1, n. 27, p. 383-406.

MORTATTI, Maria do Rosário R. (2018). Entre a literatura e o ensino: a formação do leitor. São Paulo: Editora Unesp Digital. 
NAKAGOME, Patrícia (2015). Literatura e/ou educação. Via Atlântica, São Paulo, n. 28, p. 89-103, dez.

REZENDE, Neide (2013). Apresentação ao leitor brasileiro. In: ROUXEL, Annie; LANGLADE, Gérard; REZENDE, Neide (Coords.). Leitura subjetiva e ensino da literatura. São Paulo: Alameda. p. 7-18.

REZENDE, Neide; DALVI, Maria Amélia (2011). Ensino de literatura: o que dizem as dissertações e teses recentes? DLCV, João Pessoa, v. 8, n. 2, p. 37-58, jul./dez.

REZENDE, Neide; OLIVEIRA, Gabriela (2015). Aula de literatura no ensino médio: escombros do texto ou leitura literária? Revista Todas as Letras, São Paulo, v. 17, n. 3, p. 13-24.

ROUXEL, Annie (2012). Práticas de leitura: quais rumos para favorecer a expressão do sujeito leitor. Cadernos de Pesquisa, v. 42, n. 145, p. 272-283, jan./abr.

ROUXEL, Annie; LANGLADE, Gérard; REZENDE, Neide (Orgs.) (2012). Leitura subjetiva e ensino de literatura. São Paulo: Alameda.

SIMARD, Claude; DUFAYS, Jean-Louis; DOLZ, Joaquim; GARCIA-DEBANC, Claudine (2016). Didactique du français langue première. Bruxelles: De Boeck.

SOUZA, Rodrigo Matos (2012). Leitores, leitura e círculos: uma perspectiva metodológica. Ponto de acesso, Salvador, v. 6, n. 1, p. 92-107.

YUNES, Eliana (1999). Círculos de leitura: teorizando a prática. Leitura: Teoria \& Prática, Porto Alegre, n. 33, p. 17-21.

YUNES, Eliana (Org.) (2002). Pensar a leitura: complexidade. Rio de Janeiro: Editora PUC Rio; Loyola.

ROSENBLATT, Louise (1994). The reader, the text, the poem: the transactional theory of the literary work. Carbondale: Southern Illinois University Press.

TARDIF, Jacques (1992). Pour un enseignement stratégique. Montréal: Les Éditions Logiques.

VYGOSTKI, Lev (1997). Pensée et langage. Paris: La Dispute.

\section{Nota}

Este artigo é resultado parcial de estágio de pesquisa realizado na Universidade de Montréal e financiado pela FAPESP por meio da Bolsa de Pesquisa no Exterior, processo 2017/1844-1. Ressaltamos que as opiniões, hipótese e conclusões ou recomendações expressas neste material são de responsabilidade da autora e não necessariamente refletem a visão da FAPESP. 